\title{
BRIDGING GAPS IN \\ UNDERSTANDINGS OF CLIMATE CHANGE AND UNCERTAINTY
}

Synne Movik, Mihir R. Bhatt, Lyla Mehta, Hans Nicolai Adam, Shilpi Srivastava, D. Parthasarathy, Espen Sjaastad, Shibaji Bose, Upasona Ghosh and Lars Otto Naess

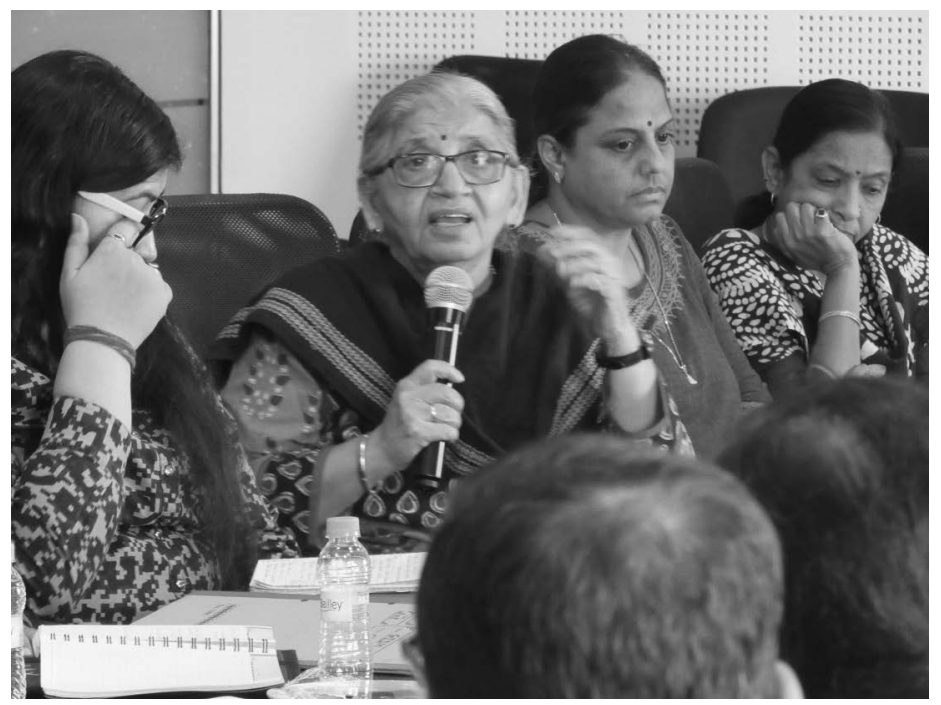

FIGURE 7.1 Roundtable engagement in Gujarat, 2018 (Photo credit: All India Disaster Management Institute).

\section{Introduction}

There is a "globalising instinct" in knowledge-making about environmental change, in general, and climate change more specifically (Hulme, 2010: 559). As discussed in Chapter 2, climate change as an object of research and action is structured globally - measurements such as temperature, precipitation and carbon dioxide concentrations are fed into models that produce global patterns 
and projections (see e.g. Edwards, 2010; Hastrup \& Skrydstrup, 2012; Schneider \& Walsh, 2019). At the same time, the impacts of climate change are largely felt locally and understandings of climate change and climate change-related uncertainties are shaped by local contexts and experiences (Heymann, 2019; Hulme, 2012). However, it has been argued that this global synoptic, which could be likened to a "God's eye view" of climate change, is so ingrained that local perspectives and historical contingencies are easily sidelined (see e.g. Dyson, 2015). Moreover, this tendency towards global abstraction can serve to marginalise and exclude the experiences of those living with climate change, in what is described as the "loss of the human scale" (Heymann, 2019: 1549).

How, then, can we build bridges between the ways in which climate change and climate-related uncertainties - both epistemic and ontological (cf. Walker et al., 2003; Walker, Lempert, \& Kwakkel, 2012) - are understood and perceived at the global and local levels? Chapter 2 in this volume explored how uncertainty is understood by scientists and policymakers, collectively referred to as the "above". This chapter puts emphasis on how diverse actors perceive and relate to each other's understandings and knowledges and how bridging gaps in understandings and perceptions can be used to inform policymaking to better reflect how realities are understood and experienced on the ground. When we talk about "bridging gaps", we are not merely talking about translating knowledges from "above" for those "below" or vice versa, rather the notion of bridging covers a more comprehensive confluence of understandings between the "above", "middle" and "below".

To address this question, we focus on the various actors who are involved in bridging knowledges as well as the spaces and practices used for experimenting with bridging, such as roundtables and techniques for co-producing knowledge, such as participatory methodologies, including photovoice. We explore how stakeholder dialogues and roundtables that seek to break down political power and disciplinary divides can provide diverse actors with opportunities to engage with and learn from different perspectives (AIDMI, 2018; Bhatt et al., 2018). Such emerging dialogues stress the importance of bringing to the fore often hidden and varied perspectives and solutions, while highlighting the need to address epistemic diversity and the power imbalances that suppress alternative knowledges and ways of valuing. To facilitate the experiment of bridging through roundtables, we organised four distinct roundtables in three different socioecological settings in India (Mumbai, Kolkata, Gandhinagar, all organised by the All India Disaster Mitigation Institute) and one in Norway (Oslo, organised by the Norwegian Institute for Water Research). ${ }^{1}$ The purpose was to bring together government officials, academics, scientists, practitioners and activists to share their perspectives and experiences and to explore how discourses on uncertainty from "below" and "above" are contested, accommodated and/or hybridised in these politically charged spaces.

As discussed in Chapter 2, the often abstract and supposedly "objective" knowledge on climate change is commonly represented by quantitative 
methodologies and more specifically, climate modelling, which tends to neglect the subjective and political dimensions of uncertainty (cf. Jasanoff, 2010). The global/local paradigm is, moreover, characterised by a distinctive difference in ways of viewing suggests the anthropologist Tim Ingold (Ingold, 2003; see also Schneider \& Walsh, 2019). Global, two-dimensional views tend to be opaque, massive, objective, detached and distant, to mention a few distinguishing features, whereas what Ingold terms spherical views are transparent, soft, subjective, close and experienced. All living beings, due to their sensory limitations, experience their environments - including climate change - in a spherical fashion. This spherical view is retained in many traditional societies and the knowledge and experience that these societies possess about aspects of environmental change have come to be increasingly appreciated and recognised (see e.g. Mahony \& Hulme, 2016; Rudiak-Gould, 2013).

The practice of bridging should involve an understanding of how knowledge and climate-related uncertainty are conceived at the different levels of "below", "middle", and "above". The experiences, knowledges and effects of climate change are local, felt by people in their daily lives, through the effects of increasing frequency of extreme weather events such as storms and cyclones, heatwaves, droughts, floods and sea-level rise (see e.g. Mehta, Adam, \& Srivastava, 2019). The globalising instincts towards knowledge-making are, therefore, "psychologically sterile" as it is beyond the horizon of people's individual experience (Hulme, 2010: 560). Local people have developed practices and strategies to deal with variability in weather and ecological uncertainty, such as seasonal migration and crop diversification (Hastrup \& Skrydstrup, 2012). Climate change radically reinforces these uncertainties. While there may be clear differential power relations between the "above", "middle" and "below", as shown in the previous chapters, we do, however, need to tease out how conceptions and understandings are translated across different domains, to explore the potential for negotiating and bridging knowledge practices (see e.g. Hulme, 2010; also Mehta et al., 2019).

For example, through his anthropological work on how climate change is experienced on the Marshall Islands, Rudiak-Gould (2012) points to the need to appreciate how climate change is being translated. He notes that

public knowledge of global warming depends on the translation of climate science from specialist communities to citizens and from scientific language to the vernacular; yet, no two cultures or languages being perfectly commensurable, this process of translation necessarily entails a transformation of the climate change concept

and teases out the implications for local understandings of climate change (RudiakGould, 2012: 46). Further, as argued in the Introduction, the ways in which the "above" and "below" conceptualise uncertainty differ markedly in terms of the spatial and temporal emphases. Uncertainty from "below" and uncertainty 
from "above" are culturally and socially embedded in local institutions, practices and power relations. While various forms of climate-related uncertainty have been identified and explored within the context of science (e.g. Smith \& Stern, 2011; Stirling, 2010), differences in the sources and culture of knowledge across perspectives will entail forms of uncertainty not captured by scientific terminology. Understanding and reducing these forms of meta-uncertainty, arising from the interaction of perspective-specific uncertainties, must be one of the goals of the bridging discussed here.

Gaps in knowledge and understanding between science and local perspectives are also linked to communication within the "above". The history of modern science has pointed out the dangers of extending isolated lessons across both time and space and the folly of letting elegant but inappropriate scientific ideas take root in bureaucracies and extension services (Barrett \& Wittgenstein, 1978; Li, 2007). The interrelated models of ecology, resource management and property rights used to stigmatise mobile pastoralism as inherently inefficient and environmentally destructive represent a widespread and persistent example (e.g. Fairhead \& Leach, 1996; also see Chapters 3 and 4, this volume). The conflicts and abuse that attend such panaceas are attributable to the failure of science to sufficiently absorb local feedback but also to the complexity of the science-policy interface (see Chapter 2); and they thus serve to undermine faith in both policymaking and the science that informs it. Climate change science, with its globalising tendency and reliance on educated guesswork, is surely not immune to these hazards.

In this chapter, we highlight how, in historical terms, subjective accounts, stories and narratives formed important parts of scientific practices more generally, later to be eclipsed by approaches that focused more narrowly on models and objectivity. While practices of knowledge-making are again opening up more generally, with calls for more democratised ways of knowledge-making (e.g. Lidskog, 2008; Stirling, 2006) and with traditional or indigenous knowledge gaining greater appreciation (see e.g. Huntington, 2011; Masinde, 2012; Masinde, 2014; Nakashima, Krupnik, \& Rubis, 2018; Nakashima, McLean, Thulstrup, Castillo, \& Rubis, 2012; Nyong, Adesina, \& Elasha, 2007; Speranza, Kiteme, Ambenje, Wiesmann, \& Makali, 2010; Williams \& Hardison, 2013), there are issues of how climate change science is being framed, translated and understood. While co-production offers a potentially fruitful basis on which to bridge knowledge gaps, the concept and how it is employed needs careful consideration. We then go on to describe attempts at bridging in the Indian context in more detail, relating how roundtables that sought to bring together experts and laypeople, representatives from the "above", "middle" and "below", engaged with one another in dialogues and exchanges of ideas and perspectives in efforts to bridge the gaps in understandings and perceptions across the different domains. We discuss these experiences, before rounding off with some concluding reflections. 


\section{Climate change and the practices of knowledge-making}

\section{The ebbs and flows of opening and closing down plural practices of knowledge-making}

The tendency towards abstractions and generalisations in current climate science is, in part, intrinsic. As scientists working with big data are the only ones "able to identify, define and characterise climate change", they indirectly shape what counts as the human dimensions of climate change (Goldman, Turner, \& Daly, 2018: 2). Another aspect relates to the fact that climate science is intrinsically transdisciplinary, drawing from atmospheric physics and chemistry, environmental science, chemical engineering, chemistry, mechanical engineering and hydrology, among other fields and sub-disciplines. Many scholars have criticised such abstractions, calling for more nuanced approaches and understandings of what counts as climate change, how it is known and unevenly experienced and highlighting the power dynamics at play (Eriksen, Nightingale, \& Eakin, 2015; Nightingale, 2016; Watts et al., 2017).

This tendency towards abstraction manifests itself in other fields of scientific inquiry too, as reflected in the work of Mazel-Cabasse (2017: 343) for seismology:

Yet, in seismology, like in many other scientific domains, progress of research over the last century has favoured the movement from subjective accounts to instrument-produced data, allowing for the development of predictive models and probabilistic conceptions of earthquake risk. In the process, earthquakes have become more abstract objects of science, defined mainly by complex mathematical operations and modelling.

The historian Deborah Coen (2012) relates how, in the 19th century, "scientific description of an earthquake was built of stories - stories from as many people, in as many different situations, as possible". Coen examines seismology's history as a form of "citizen science". In the 19th century, standing networks of seismic observers transformed earthquakes into natural experiments at the nexus of human behaviour and planetary physics (ibid.). There are similar experiences from volcanology, for example, how the eruptions of Krakatoa and its effects on global climate have been studied through paintings of clouds. ${ }^{2}$ In another example of historical analysis of knowledge practices, Carey (2010) provides an account of glacial melting in the Peruvian Andes, elucidating the complex climate-society interactions underlying glacier environmental change and emphasising how economics, power relations and cultural perceptions all form part of the story. Further, the spatial turn (Agar \& Smith, 2016; Ophir \& Shapin, 1991) invited geographers into the discussion of scientific knowledge-making about the environment, which emphasised taking "place" and "space" seriously in environmental knowledge-making and appreciating the complexity of 
social-ecological interactions (Grevsmühl, 2016). The scientific discipline at the forefront of the global scientific effort to document climate change - climatology - has undergone an evolution from one of a "clearly on humans-oriented climatology" (Flohn, 1954: 11) towards "globalising reductionism" that operates only at scales (global) outside the graspable human realm (Heymann, 2019).

Such historical accounts and the more recent efforts to pay attention to space and place bring to the fore the role of subjectivity, political economy and power in shaping knowledge production practices that help inform understandings of society-nature relations. This demonstrates how the contemporary call to open up for a broader understanding of knowledge production practices is not necessarily novel, as past practices of scientific inquiry encompassed more comprehensive conceptions of what constituted knowledge.

\section{Constructing bridges - appreciating plural practices of knowledge- making and valuation}

Thinking about bridges between the "below", "middle" and "above" involves thinking about multiple forms of "local" knowledges and understandings of uncertainty and change and how these can speak to scientists and policymakers - and vice versa. The notion of bridging, then, does not merely refer to a simple construct between one set of knowledges or epistemologies and another, but rather refers to the fluid and dynamic linkages across disciplinary and sectoral boundaries and across multiple scales and actors at the "above", "middle" and "below" or "local". What, then, is "local" knowledge? One definition of local knowledge, drawn from the policy sciences, states that local knowledge is "knowledge that does not owe its origin, testing, degree of verification, truth, status, or currency to distinctive professional techniques, but rather to common sense, casual empiricism, or thoughtful speculation and analysis" (Lindblom and Cohen, 1979: 12, cited in Corburn, 2003: 421). The anthropologist Clifford Geertz defined local knowledge as "practical, collective and strongly rooted in a particular place", which constitutes an "organised body of thought based on immediacy of experience" (Geertz, 1983: 75, cited in Corburn, 2003, p. 421). There is, however, a need to avoid reifying local and expert, or professional, knowledge as monolithic entities (Agrawal, 1995; Wynne, 1996; cited in Corburn, 2003). Further, local knowledge is often "held by members of a community that can be both geographically located and contextual to specific identity groups" (ibid.: 421).

One issue that emerges when discussing different types of knowledge at different levels is what might be termed the politics of valuation. A certain politics of knowledge and valuation results in particular domains (especially so-called hard science) gaining authority over the others. Yet, all forms of knowledge (including so-called expert knowledge) are culturally and socially embedded and moulded by particular social, power and gender relations. Models are also embedded in narratives and storylines about a future based on certain 
assumptions (Hajer, 1995; Roe, 1994) but through a range of political practices and boundary-ordering devices gain authority over other forms of knowledge (Heymann, 2019; Shackley \& Wynne, 1996; Wynne, 1996).

\section{Framings of climate change and the question of visibility and attribution}

As alluded to above, the gap between expert and local knowledge stems, in part, from the fact that climate change is understood predominantly as an intrinsically global and long-term phenomenon. The "gulf between brute, visible reality and climate change is crowded with arcane mathematics, high-tech measuring devices and inhumanly large temporal and spatial scales" (Rudiak-Gould, 2014: 121). However, if one instead labels it "long-term weather change", this is not inaccurate and it narrows down the gap, as "weather" is something everyone can relate to, as we noted in the chapter on Kutch (Chapter 4). As argued by RudiakGould 'the words 'long-term' and 'change' spread the word 'weather' out over a period of time, rendering the climate/weather distinction moot" (RudiakGould, 2013: 123). Moreover, one could have considered using concepts such as "pervasive" or "multi-sited" to substitute for the "global" (Rudiak-Gould, 2013: 123). The tendency has been towards understanding climate as a globalised, abstract, invisible phenomenon - a statistical and technical concept described by distributions of variables as temperature and precipitation - in contrast to weather, which is immediate, visible and subjectively experienced. Another reason for globalised conceptions of climate is also the interconnectedness of, and interactions between, regional weather phenomena such as El Niño and the Indian Summer Monsoon (as discussed in chapter 2). The issue of whether climate change is visible brings to the fore the deep divisions between different disciplinary fields (Rudiak-Gould, 2013). The "invisibility" camp argues that "anthropogenic tampering with the atmosphere does not result in specific weather events but merely 'loads the dice' in a stochastic system; no individual (visible) event can be attributed with certainty to climate change" (Allen, 2011; quoted in Rudiak-Gould, 2013: 121). While some have softened their stance somewhat, conceding that individual events can, indeed, be attributed to climate change, the conflict stems from a larger battle of authority and politics. Scientists' "insistence on describing the phenomenon with the terms 'global' and 'climate' does not stem merely from a desire for terminological exactitude but from a particular political outlook in which scientific authority is central" (RudiakGould, 2013: 121).

There are challenges with visibility too, though, for example, that climate change is what Rudiak-Gould terms a "promiscuously corroborable" concept, it can be used to explain all sorts of phenomena experienced by local communities (Rudiak-Gould, 2012: 52). "A middle way between understanding climate change as abstract and invisible and as local and visible, is to render it visible through translating from the useable realm of climatological abstraction into 
the (seeable) realm of local narratives" (Marx, 2017; cited in Rudiak-Gould, 2013: 128) and vice versa: "sensory experience on the ground breathes life and urgency into desiccated expert assessments, while scientific generality serves to unite disparate communities around the travelable concept of climate change and methodological scepticism provides a cautionary counterpoint to over-exuberant local attribution" (Rudiak-Gould, 2013: 129). This tension also came out in our roundtables where policymakers often characterise these sensory experiences as anecdotal and not something that is driven by generalisable facts (see Chapter 3).

\section{Co-production and bridging}

Thus, there is a need to bring together these sensory experiences and scientific generality. One promising avenue is the concept of co-production. The increasing appreciation of the existence of multiple epistemologies has led to efforts that aim towards co-producing knowledge (e.g. Goldman et al., 2018; Jasanoff, 2004b; Lane et al., 2011) which plays an essential part in efforts to bridge knowledge gaps. The concept of co-production emerged from diverse theoretical and disciplinary perspectives across the social sciences and humanities (Bremer \& Meisch, 2017). One way of defining co-production, espoused by many science and technology studies scholars, is through using it to capture the interdependencies and mutual constitution of nature and society. In science and technology studies (STS) terms, co-production can either be interactional, that is, concerned with epistemic debates around scientific authority and expertise and the interface between science and politics or constitutive. Constitutive co-production raises more profound issues about how knowledge production shapes social order and science-society and politics-nature relations (cf. Jasanoff, 2004b). It could be helpful to distinguish between what Goldman et al. term "instrumental co-production" (Goldman et al., 2018: 1) and other forms of co-production. Instrumental co-production basically refers to projects where attempts are made to fit local knowledge into existing schemes of conventional science and draws on the early usages of co-production from the 1970s, which was largely associated with the idea of "co-producing" public services (e.g. Ostrom, Parks, Whitaker, \& Percy, 1978).

Some scholars prefer the term joint knowledge production (e.g. Hegger \& Dieperink, 2015) to avoid the potential elision of processes that aim to engage in bottom-up collaborative knowledge-making, that is, where there is no attempt to mesh local knowledge with pre-defined sets of categories or typologies. Other terms include hybrid knowledges (e.g. Benessia et al., 2012; Reid, Williams, \& Paine, 2011; Thomas \& Twyman, 2004), hybrid epistemologies (e.g. Burnham, Ma, \& Zhang, 2016) and polysemic epistemologies (Mazel-Cabasse, 2017). While these approaches are promising, there are obvious challenges. How does one assess the salience, validity and legitimacy of coproduced, or hybrid, knowledge? Integrating different types of knowledge is inherently complex, "with no single optimum approach for integrating local and scientific knowledge" (see also Jasanoff, 2004a; Raymond et al., 2010: 1775). 
Moving beyond the appreciation of multiple epistemologies, Goldman et al. (2018) draw our attention to the notion that people engage in world-making through particular practices and thus there are not only multiple epistemologies ways of knowing the world - but also multiple ontologies or practices of worldmaking. Maasai pastoralists might not necessarily experience climate change first and foremost as temperature and precipitation change, but as changes in the ability to predict the weather and changes in vegetation and animal behaviour (Goldman, Daly, \& Lovell, 2016). Similarly, in Kutch (Chapter 4), the impacts of climate change are being experienced by the local pastoralists as a cascade of uncertainties that is making their livelihoods increasingly precarious. Appreciating multiple forms of world-making challenges an assumption that "most of us hold dear: that there is one reality out there, about which we can explore different perspectives" (Goldman et al., 2018: 3). But if reality is understood as enacted in practice, then there are multiple ontologies brought into being simultaneously (Mol, 2002: 6), not just multiple epistemologies. Therefore, a comprehensive engagement with knowledge and attempts at bridging knowledge gaps needs to deal with both multiple epistemologies and multiple ontologies.

The project drew on various methodologies of co-production, such as transect walks, participatory mapping and - importantly - photovoice. These methodologies allowed the voices of the local people themselves to be heard and to bring into view often tacit and ignored forms of knowledge. Such coproduction efforts formed a necessary basis for building bridges, as they were a means to shed light on marginalised perspectives.

\section{Building bridges: The role of roundtables}

\section{Uncertainties in the Indian context - Mumbai, Kutch and the Sundarbans}

Other chapters in this volume have provided detailed descriptions of the ways in which uncertainty has been conceptualised by the "above" (Chapters 2 and 3) and the "below" (Chapters 4-6). In the following, we recap some of the main uncertainties of the three research sites, before going on to explore the role of roundtables in bridging divides in understandings and perceptions of uncertainty and climate change.

The coastal megacity of Mumbai is one of the largest and most densely populated urban agglomerations in India, with a population of around 20 million people. It is home to a burgeoning service and manufacturing sector as well as the financial heart of India's economy. It is also a city characterised by deep social inequalities and exclusions. Mumbai has a unique coastal ecological identity, with mangroves, marshlands, salt pans and wetlands that function as potential buffers against floods and extreme weather events but that are increasingly coming under threat from urban development projects and pollution (cf. Chapter 6 on urban flooding in Mumbai). 
Islanders in the Sundarbans in West Bengal have had to contend with shocks such as cyclones and floods, sea-level rise, changes in its deltaic ecology and socioeconomic marginalisation. Climate change is causing frequent embankment breaching; loss of land, homesteads and other assets and salinity intrusion, leading to the depletion of the traditional agro-fishing economy and straining the islanders' coping capacities (cf. Chapter 5 on the Sundarbans).

The semi-arid district of Kutch in north-western Gujarat faces multiple climate-related challenges, such as more frequent droughts and prolonged periods of high temperatures as well as increasingly erratic rainfall patterns. Such changes are heavily affecting local people's livelihoods, including agriculture, livestock and fishing. Climate change-related challenges are exacerbated by pressures from industrial development in some of the most eco-sensitive zones, leading to a cascade of uncertainties for local people as their livelihoods become increasingly precarious (cf. Chapter 4 on Kutch).

\section{Emerging issues from the roundtables}

Climate change is like an elephant in the story, and while people see different things (ear, tail, trunk), we need to look at it as one whole animal.

(January 2018, Gandhinagar Roundtable)

This quote from an NGO participant nicely summarises the many ways in which climate and its associated uncertainties are characterised by actors from the "above", "middle" and "below".

As part of the project, we organised four roundtables, one in Norway and three in India. Roundtables were organised in Mumbai, Gandhinagar (for Gujarat and Kutch) and Kolkata (for Sundarbans) in January 2018, bringing together perspectives and experiences of government officials, academics, practitioners and activists. These were built on an earlier roundtable organised in Oslo in August 2017. The aim was to understand the way climate change and uncertainty are experienced and understood by diverse stakeholders in order to explore ways to foster transformative, socially just and inclusive development to cope with the challenges of climate-related uncertainty. The three roundtables in India were rooted in their site-specific contexts (the rapidly urbanising coastal metropolis of Mumbai, the deltaic islands of the Indian Sundarbans and the dryland dynamics of Kutch in Gujarat). The roundtables were quite distinct in both orientation and scope, due to the different locations (e.g. whether at a university, government institute or a neutral seminar venue) and the role played by the local partners and co-hosts. In Mumbai, the audience at the Indian Institute of Technology (IIT-Bombay) largely comprised natural and social scientists, with some NGOs and local fisher activists and the discussions revolved around academic discourses on uncertainty. By contrast, the Gujarat meeting, perhaps due to its location in the state capital (Gandhinagar), was dominated by government officials and 
policymakers from different departments, who welcomed the opportunity to engage with each other's work, alongside many researchers and NGOs. Similarly, in Kolkata, the meeting had a good mix of different scientists, researchers and NGOs as well as government officials. Power differentials were evident in all the roundtables but reflected in different ways (Mehta \& Srivastava, 2020).

The roundtables played a key role in highlighting diverse understandings of uncertainty, while simultaneously opening up opportunities for sharing and learning. For some participants, the roundtable was a new experience, and they appreciated the opportunity to engage with and learn from different perspectives. For others, the roundtable rehearsed well-known diverse views and brought to the fore the challenge of reconciling these plural perspectives (Mehta \& Srivastava, 2020).

All the roundtables began with a powerful photovoice presentation highlighting the precariousness of ordinary people to climate-related uncertainties (e.g. erosion of lands in the Sundarbans due to sea-level rise or the changing nature of rainfall and droughts and their impacts on livelihoods in Kutch) and how they make sense of, live with and adapt. The photovoice presentations from the three sites helped bring the voices of the communities to the policymakers through capturing their understandings of coping and adapting with livelihood hazards in the remote sites and through showcasing their indigenous understanding and insights related to climate change uncertainties, which are intrinsically geographical and placebased. These alternate views offered policymakers a valuable window into the community's understanding of issues related to mild and extreme uncertainties. These uncertainties are further compounded by wider socio-economic changes, which often destroy key ecological resources such as mangroves (on the Mumbai and Kutchi coast) that both protect the vulnerable coastline and are also key to the livelihoods and well-being of the local communities.

The presentations facilitated roundtable participants' understanding of how people living with climate change make meaning themselves, and construct what matters to them through reflecting on their own community portraits and voices and on what questions can be linked into making inclusive policies and importance of convergence and interrelation between the different stateand private-led adaptation interventions. By bringing in the communities' lived experience, the roundtables advocated for a more integrative process consisting of bottom-up and top-down actions, local and scientific knowledge and a vast array of stakeholders that would help bridge the separation of knowledge and action.

\section{Diverse epistemologies and framings}

One characteristic that clearly came out was the diversity of epistemologies and framings. People with different disciplinary backgrounds were framing climaterelated uncertainties in distinctly different ways. Yet there appears to be an increasing consensus that interdisciplinary research is important in connecting various dots and bringing together scientific findings and models across fields 
such as climate/hydrology. A participant with a natural science background describes the trend within meteorological/climate research as follows:

(...) I have been working as meteorologist for 40 years, and there is significant change in our behaviour (...) when I started, we were the kings (...) we decided what people should know. Now we provide forecasts and projections and people have a lot of sources (...) we need IT people/ meteorologists, communication experts and social scientists; now it's a multidisciplinary task. There is scope for cross-learning too, between sociological perspectives and policy action.

(January 2018, Mumbai roundtable)

While information sharing is key in mediating such processes, it was pointed out that training exercises for bureaucrats/policymakers can lead to better interpretation of information and more efficient decision-making. This was reaffirmed by participants from "above", "middle" and "below".

Different participants had different entry points in this discussion and looked at climate change through the lens of their sector/departments or epistemological positions. For the scientists in Gujarat, climate change is real and certain and is measured through key variables such as temperature, rainfall, sea-level rise and concentration of GHGs in the atmosphere (see Chapter 4). One scientist referred to a recent study suggesting that there would be drastic changes in the summer and winter temperatures in Gujarat and this would have significant impacts on agriculture, livestock and water resources. He argued that the "most important thing to bridge gaps on climate change and uncertainty is to focus on local scenarios of climate change" (Interview January 2018, Mumbai). Whereas for another scientist (IIT-Bombay) in Mumbai, the most important issue was that "hybrid knowledge is required to solve the problem (...) for example, hydrological as well as climate models should be combined to give overall results."

In the Mumbai roundtable, a civil society representative emphasised the need to understand the city as a fluid space, rather than a static entity. Understanding the city as an integrated urban space, paying attention to its geography and multiple constituents highlights how climate change and climate science are framed. Such an imagining of the city as greater than the sum of its constituent parts is also important for engendering social transformations that are emancipatory in nature. For instance, in imagining cities as fluid spaces, a neighbourhood can be viewed as the basic unit of transformation. In the Mumbai roundtable, the neighbourhood approach came up as an important concept for the fishing community that was dealing with climate-related uncertainties (see Chapter 6). The neighbourhood approach, which begins with empowering neighbourhoods where specific communities (like the fishing community of Mumbai) are concentrated, can then be replicated, contextualised and scaled up to cover entire cities. Such an approach can be an effective pathway to social transformations. 
Similarly, vulnerable environments like the Sundarbans require pro-poor adaptation as well as the strengthening and protection of local ecosystems and biodiversity, especially mangroves, in a people-centric way. At the roundtable in Kolkata, it was discussed that various knowledge regimes and experiences, including scientific, technical, administrative and everyday practices, need to come together to plan for alternative solutions to the problems this region faces. In this regard, the state should facilitate spaces to enable sharing between policymakers and local-level policy implementers, NGOs and communitybased organisations (CBOs) as well as local communities' own experiences and responses (see Chapter 5). For example, the Sundarbans Affairs Department may need to take leadership in the facilitation of such a platform.

\section{Politics of valuation}

Another key theme was the politics of valuation. Several participants emphasised the need to appreciate the importance of ecological elements, such as mangroves. A community leader, from the Koli community in Mumbai, emphasised that port development activities in their area on the outskirts of Mumbai lead to a "loss of livelihoods for future generations" and "mangroves play a highly significant role for fishing and acts as the breeding site for fishing" but that "authorities and policymakers do not have local or indigenous knowledge about seawater pathways, and inter-tidal flows". This, in turn, leads to faulty attributions, wherein the government attributes overfishing as the major reason for decreasing fish catch (January 2018, Mumbai Roundtable). It was also pointed out that comparatively little attention had been given to flood proofing in planning, largely due to a lack of understanding of the importance of ecological elements such as mangroves in flood risk mitigation. An atmospheric and climate scientist substantiated that when it comes to ecosystem services offered by mangroves, continuous evaluation is needed, even though quantitative monitoring remains difficult. The question was raised in response to the emphasis on the need to quantify value, whether one should not find alternatives to monetary valuation? This is not so much a question of economic value, as a question of political priority - it should be the local authorities' primary task to protect and prioritise local livelihoods. It is also a question of culture - cultural values, anchored in livelihood practices, exist, but do not find their way into standardised assessments as pointed out by the Koli community leader. Such assessments, framed as they are by political economy actors (corporate actors, contractors, state), are not geared towards acknowledging uncertainties, diverging valuations, livelihoods or longterm ecosystem dynamics. Traditional and hybrid forms of knowledge can be of importance in efforts to achieve more balanced and sustainable development, yet is usually ignored.

Often, such exercises tend to be opaque and closed and efforts are needed to open these exercises up, to make them more transparent and accountable. Thus, alternative approaches to the monitoring and evaluation of uncertainty 
and transformation actions are needed. These include standard assessments such as environmental impact assessments (EIAs) and social impact assessments (SIAs) which need to be reframed along more inclusive terms and become more participatory, to broaden up their epistemic base. A participant in Mumbai asked “(...) can EIAs and SIAs be impartial when funded through the project?". The major challenge is bringing in transparency to mandatory exercises like public hearings in EIA, which take place as closed and opaque exercises. Returning to the issue of flood proofing, it is important to look at past disaster response mechanisms with respect to flooding and what scope for learning exists and what opportunities there are for incorporating a wide range of perspectives, including that of the general public. Thus, all the three roundtables had discussions on qualitative approaches to understand the extent of climate-related uncertainties and the scope of transformation. Roundtables with a diversity of actors across different levels can be a way to achieve this.

\section{Attribution, causality and (deflection of) responsibility}

Another issue that was frequently discussed was the question of attribution and, aligned with this, the question of responsibility, or rather, the deflection of responsibility. According to a scientist from IIT-Bombay, attribution science (i.e. can the cause of extreme weather events be clearly traced to climate change) is not very advanced and suffers from serious limitations. However, as discussed by Mehta et al. (Chapter 2), policymakers are not concerned about whether a phenomenon can be attributable or not to climate change. What matters to them is response, not cause. The problem is, however, that limited knowledge on dynamics of various systems, as well as the sensitivity of certain information, prevents the creation of more confident projections and creates uncertainty. Attribution, thus, becomes an important question when seeking to comprehend causality to risk and vulnerability. Policymakers, disaster mitigation officials and politicians tend to blame "outside forces", thereby deflecting responsibility and accountability.

\section{Knowledge and integration of lived experience}

The need to integrate knowledge of lived experience of impacts was acknowledged across the roundtables. Translating this acknowledgement into existing research methodologies can prove to be a challenge, especially for modellers, as noted by one of the participants in the Oslo roundtable. In the Gujarat roundtable, policymakers viewed themselves as making up the "middle", as being the ones whose task it was to communicate climate science to local people. Participants acknowledged that climate change impacts are most vigorously felt at the local level, especially in terms of the changes in water supply and resources, health, livelihoods, forests and biodiversity. There was, however, a sense that local people were a form of "black box", policymakers knew very little about how they were affected by climate changes. This reiterated the standard top-down 
understanding of policymaking and implementation where local people are framed as beneficiaries rather than equal partners.

An example of how to engage local communities and local knowledge was offered by an NGO in Gujarat. In the projects, local community consultations are being organised around water, livelihood and ecosystem restoration, and they pointed out that more efforts are required to work on stakeholder perceptions related to climate change and uncertainty. An academic talked about vernacular architecture to understand ways of dealing with uncertainty (how people live, eat, sleep, experience and recover from trauma). There was also a suggestion that children are also important stakeholders when it comes to uncertainty and projects with a decided focus on children and uncertainty can be very useful (January 2018, Gandhinagar Roundtable).

Another concrete example that came up in the Gujarat workshop focused on health, and how changes in humidity has health impacts. This is not recognised at all by policymakers, demonstrating how more knowledge about the impacts of climate change on local people can be integrated into policymaking to make it more targeted and effective. For instance, it was pointed out by one of the participants at the Gandhinagar roundtable how climate and humidity, as variables for climate change, may not make a lot of sense to policymakers but impacts on health are more tangible and can gain policy traction. Policy practitioners are still trying to understand the impacts of new diseases and how adaptation to climate change requires behaviour change, which is quite complex. This links up to the earlier discussion around the visibility/invisibility of climate change. This insight was surprisingly prescient, given that such problems have come to the fore during the current COVID-19 pandemic.

There was also discussion about factors that exacerbate the lived experiences of climate-related uncertainty. For instance, in the Mumbai roundtable, several participants pointed out how informality reinforces the lived uncertainty, relating how small businesses in the informal sector were hardest hit during flooding. They keep limited stocks of inventory and obstruction in supply chains and production facilities have immediate cascading effects that dent income and employment opportunities. In the absence of baseline data, it is difficult to make accurate assessments of costs, damages and vulnerabilities. Insurance coverage is not available to cover losses for these small enterprises. In the formal sector, on the other hand, losses from natural disasters are often covered - displaying an unequal adaptive capacity and recovery. This demonstrates how informality and uncertainty are closely linked.

Clearly, the lived experiences of the people engaged in the informal sector are not always accounted for in framings of climate-related uncertainties by the "above" and "middle" levels. The disruption to business continuity faced by informal enterprises in the wake of climate stresses and shocks can have a lasting impact on the lives of people employed in such enterprises. This disruption and loss of livelihood opportunities represent the local-level imaginings and understandings of climate-related uncertainty that is often not integrated into 
policymaking. For instance, India has one of the largest informal workforces in the world. The 2018-2019 Economic Survey of India estimates that almost $93 \%$ of the country's total workforce works in the informal sector. This large chunk of the working population does not have access to insurance or other risk pooling mechanism, leaving them extremely vulnerable the adverse impacts of climate change uncertainties (see also Patankar \& Patwardhan, 2016). In the Mumbai and Kolkata roundtables, insurance for informal enterprises came up as a potent method for them to deal with uncertainty. Similarly, piloting large-scale insurance and other risk-pooling options can also have large-scale implications on the future of work in a largely informal economy like India. This represents a possible pathway to social transformation.

There was more controversy, however, relating to how people's perceptions of climate change could be integrated more directly into projections and modelling (see Chapter 2). In the Mumbai roundtable, one theme that was explored was the possibility of incorporating social perspectives into modelling practices. According to a citizen scientist, it is a question of "what skills can tolerate other skills" and models require re-examination with respect to incorporating feedback. Some efforts are already emerging, for example, people mark places of local importance/vulnerability (curves, ditches, etc.) not captured in other modelling exercises through smartphone apps or other means, which subsequently feed into models and projections. Several academics and civil society actors in the Gujarat roundtable agreed that communities do have a wealth of information and that there is a need to have a local decentralised information centre, which could act as the connecting point between the "below" and "above". It was suggested that "capacity building" is not just required at the level of the community but also at the level of decision-makers who need to be sensitised to local understandings and lived experiences of climate change and appreciate the multiple interconnections of climate-related uncertainties at the local level. Therefore, policymakers and scientists need to understand the local languages or representations of climate change.

Another issue related to the integration of lived experience is the notion that landscapes are heterogeneous. Policymakers' significant lack of knowledge of the Sundarbans, for instance, is, in part due to the heterogeneity of the Sundarbans. As one researcher pointed out, the Sundarbans is not one place, but many. The "many Sundarbans" refers to various geographical locations, such as the coastal pockets, the deltaic Sundarbans, and the mainland part. Impacts from climate change are, therefore, highly localised and people are responding to the varied manifestations of climate change at the micro-scale, which must be appreciated, acknowledged and accommodated by policymakers.

\section{Institutional complexity and fragmentation}

Uncertainty due to heterogeneous landscapes and institutional complexity/ fragmentation was a theme generating much discussion. The case of mangroves 
and fisheries provided a peculiar case of natural resource management that has fallen between the cracks of various government departments. In Uran, near Mumbai, fishing predominantly takes place in mangrove areas during low tide. However, the land in question is mainly under the purview of the forest/ revenue department. The Fisheries Department has little influence, as its primary responsibility lies beyond the shoreline. This problematic interface between land and sea areas in the inter-tidal zone has created uncertainty that complicates governance efforts and institutional support of traditional fisherfolk. The Mumbai roundtable highlighted the possible benefits of collaboration between researchers and fishers by consistent knowledge generation to back up their legal and other struggles, a process that is not easily amenable to quick decision-making. As one participant expressed, there is a "need to spend time with the community to understand their issues."

Heterogeneity and fragmentation were key issues in the Sundarbans too. The "above" has many conflicting views depending on how they utilise resources and how they understand "development". This is reflected mostly in the divergence between goals and strategies of the line departments. Similarly, the "above" is also constrained by the government's prerogative to control resources and funding sources for the development of the Sundarbans. This acts as an obstacle in efforts to promote collective action on the part of actors in the "middle". For instance, at the Kolkata roundtable, a researcher working in the Sundarbans' health system for several years pointed out:

When we started working in the Sundarbans, we asked the Department of Sundarbans Affairs about their plans for people's health. They stated that it is the responsibility of health department. Again, when we further probed to the social developmental aspects of health to the State Health department, they said it is not their area of concern.

(January 18, Kolkata roundtable also see Chapter 5)

Such obstacles are also debilitating to the agency of "below" actors to participate in making decisions in situations of uncertainty. As has already been established, the actors from "below" seldom have their voices captured or heeded by "above" actors when it comes to taking decisions regarding uncertainty. This lack of agency is exacerbated by institutional complexity and overlaps. Institutional fragmentation of responsibility can easily lead to a sense of apathy, as is the case in the Sundarbans (see also Parthasarathy's work on the issue of institutional and epistemological "balkanization” (Parthasarathy, 2016)).

One theme that did not directly come from any of the roundtables, but which was indirectly raised in all of them, was the issue of asking the right questions about uncertainty and its concomitant impacts on society, economy and environment. More importantly, there needs to be consideration about who asks these questions. The agency of "above", "middle" and "below" actors is skewed in raising questions about uncertainty and ceding some space to actors 
from "below" in raising such questions would lead to a more integrated and holistic understanding of uncertainty.

\section{Lack of knowledge/insufficient communication}

The roundtables also highlighted how uncertainty was grounded in a lack of knowledge and insufficient communication, which was, for instance, the experience in Gujarat. Some argued that decision-makers need to be sensitised to the local understandings and lived experiences of climate change and to the multiple interconnections of climate-related uncertainties at the local level. The participants agreed that "understanding of climate change across the three levels has to improve. Even I do not understand enough about it (...) we need to speak to those who do and understand the limitations. This is why this [bringing people together] is on the dot" (January 2018, Gandhinagar Roundtable). A number of participants agreed that there exists an information gap between the "above" and "below", with poor communication between departments, between local people and the policymakers, and between scientists and policymakers.

Several participants in the Mumbai roundtable also emphasised how there was a need to improve communication, while also conveying problems relating to uncertainty and attribution. Lack of knowledge and communication issues came out as highly salient issues in the Sundarbans case as well. For instance, a climate scientist working in the area noted that Bangladesh has well-researched locallevel scientific data on sea-level rise, salinity levels and subsidence or erosion rates. The Indian side does not have the same level of detail. While climate scientists based in West Bengal have worked on climate modelling of the Sundarbans, they agree that data gaps prevent better and more accurate projections. Data gaps also persist in identifying people's coping strategies. An example pertains to whether migration is a seasonal coping or permanent adaptation strategy, as there is scant official data on the actual number of migrants. As discussed in Chapter 4 on Kutch, policymakers usually like to be certain about the course of action that they can work, such as likely scenarios, but not with "something that is highly uncertain” (January 2018, Gandhinagar Roundtable). To a decision-maker, or at least from an economist's viewpoint, the question would be "what can I do to limit losses in case my expectations fail?" so that is the financial risk, that is the risk of poor women in India as well, and there is no correspondence between these two ways of understanding risk. Because, to a decision-maker, you cannot separate risk from decisions, meaning also that risk cannot be expressed in terms of one measure. It is a question of how are you controlling, who are you asking, and what is the objective of that person? For policymakers, the types of uncertainty could be summed up as situations where one can address uncertainty through improving information and communication (epistemological) and where one cannot fix uncertainty (ontological). Policymakers may be able to address the first level of uncertainty. An interesting observation was that many of the policymakers considered themselves as the "middle" in bridging the divide 
between the scientists and local people. A senior policymaker stated: "We can act as a bridge, we understand below and top and thus can help bridge [the gap]." In the Gujarat roundtable, it was highlighted that there is a tendency towards an elite bias in climate change, with most of the information being in English and there is a need for more vernacular representations of climate change. As a participant highlighted:

When we work with grassroots (...) they say things, but it is not very well articulated. There is lot of literature in English but not disseminated in Gujarat (...) we need to involve below and also build capacity of local institutions.

(January 2018, Gandhinagar Roundtable)

\section{Discussion and concluding reflections}

This chapter has focused on the potential of roundtables to bridge the gap between what policymakers do and the experiences and understandings of local people regarding climate change and uncertainty. The roundtables brought together experts in diverse fields, representatives from civil society and other actors, in an attempt to foster dialogue and deepen our understanding of the plurality of perceptions and how one can work towards bridging the gaps in understandings and perspectives.

The brief historical overview at the beginning of this chapter emphasised how knowledge-making practices in environmental realms were once potentially open to being broad and inclusive through incorporating a range of diverse narratives and stories. Subsequently, however, this openness was narrowed down to being more concentrated to a specific or relatively more closed form of knowledgemaking. In recent times, there has been a re-opening of ideas and framings around knowledge-making, acknowledging the multiple forms of knowing. This is, in part, reflected through the increasing appreciation of local, indigenous or traditional forms of knowledge in much of the environmental science and governance literature. This is, to some extent, true for climate science as well. However, as discussed by Mehta et al. in Chapter 2, there still is a long way to go and part of the reason for this is, as pointed out, the "global" nature of climate science and how it tends towards knowledge-making that is not aligned with on-the-ground understandings, vulnerabilities and realities. Added to this is the often siloed nature of governance which is a barrier to bringing diverse knowledge into conversation Policymakers tend to base their decisions on datasets that draw on the probability of precipitation and temperature changes but have little knowledge of ground-level realities, how people themselves understand and experience climate change and climate-related uncertainties.

While there is an implicit assumption that policymakers are responsible for acting and responding to local-level realities and experiences of climate impacts, questions of attribution, causality and responsibility served to complicate such 
assumptions. The degree of uncertainty around causal linkages may, in some instances, lead to policy paralysis. Such inertia may be compounded by the heterogeneity of landscapes where impacts are experienced and the fragmentation of institutional ambits of responsibility. This was clearly illustrated in the case of Mumbai's coastal zone, where it is the Forestry Department that has the mandate for mangroves, but the Fisheries Department that claims authority over the coastal zones of which mangroves form an important element. Who should ultimately be responsible and how can such institutional barriers to action be overcome?

We have highlighted the usefulness of bringing together different perspectives and knowledges and exploring the potential role of roundtables, together with visual approaches such as photovoice, in elucidating the challenges and opportunities in doing so. However, there are multiple challenges associated with such efforts. While there was widespread appreciation of the importance of including social science perspectives, there was also concern about how to best incorporate local knowledges. What emerged from the roundtables was a rich set of issues that participants feel need to be addressed in order to foster more constructive dialogue and bridging practices across disciplinary and sectoral divides. Participants across the board agreed that greater awareness is needed around how multiple and diverse epistemologies and framings shape our perceptions of climate science and what counts as "knowledge". While there were useful suggestions as to how "scientific" facts about climate change could be better communicated to local communities - for example, through translating information into local languages - there was less clarity on how local people's knowledges and perceptions could be brought into knowledge-making and policymaking, especially when they are often characterised as anecdotal evidence (see also Chapter 2). While there were several examples of ongoing projects that explore more participatory approaches to knowledge-making and integration of local understandings and perceptions, there was also a prevalent scepticism among some scientists and policymakers about the credibility and validity of drawing on local people's knowledges because such knowledge was perceived as being "less scientific" and more anecdotal. This points to the need to open up understandings of historical practices in knowledge-making, as highlighted in the historical overview section and improving ways to understand and incorporate stories and narratives about change into the wider body of knowledge of climate science. In order words, how to make "invisible" knowledges of climate change visible. Another important issue linked to knowledge and knowledge-making concerned the politics of valuation. Critical valuation exercises of the economic, ecological and social impacts of climate change, extreme events and uncertainty from multiple perspectives are necessary to avoid the pitfalls of simplistic neoclassical models which are often used to justify environment-unfriendly and socially destructive infrastructure projects that dispossess local people and their livelihoods.

Realising that knowledge-making in the past was a broader, more comprehensive endeavour and that much is lost through narrowing down the scope 
to focus on models could help make policymakers and the "above" realise the value of bringing in more diverse, local perspectives and understandings from the "below". Thus, encouraging more qualitative approaches and reflecting on the challenges of integrating local knowledge can help deepen reflections around what knowledge is and how to think about knowledge in new ways. Key to such efforts is the realisation that spaces must be opened for local people to communicate their knowledge and uncertainties. As Jasanoff (2009) argues, the political and subjective dimensions of uncertainty at the scale of the local have to be recognised in order to achieve more effective bridging of understandings, knowledges and action. Bridging is not simply about translating knowledge, but rather it involves the generating of a vibrant traffic in understanding between the "above", "middle" and "below". In this way the global and abstract as well as local and grounded experiences are brought into meaningful conversations to create appropriate responses to climate change, while simultaneously acknowledging the limitations inherent in existing power relations and hierarchies. Through bridging gaps, we can explore possibilities for producing "hybrid knowledge spheres" in which the "below", "middle" and "above" are reoriented through thick interactions and work collectively towards transformative strategies in response to climate-related uncertainties.

\section{Acknowledgements}

We thank all the institutions that facilitated the roundtables, the Gujarat State Disaster Management Authority (GSDMA), Gujarat Institute of Desert Ecology (GUIDE), Indian Institute of Health Management Research (IIHMR), Indian Institute of Technology-Bombay (IIT-B), Norwegian Institute for Water Research (NIVA), and Department of International Environment and Development Studies (Noragric) as well as the participants for their time and active engagement. A special thank you to AIDMI for overall support and co-ordination. We would also like to thank Rohan D'Souza for constructive comments on an earlier draft of this chapter.

\section{Notes}

1 The Oslo roundtable brought together researchers, policymakers and funders to discuss uncertainty and climate change. This was the first in the series of roundtables, where the subsequent sessions would focus more on the context and challenges of the specific sites. The first roundtable in the series addressed the overarching notion of 'uncertainty' as it permeates the project work throughout.

2 See https://www.youtube.com/watch?v=MrEIT66oPqU] (accessed 15 March 2020).

\section{References}

Agar, J., \& Smith, C. (2016). Making Space for Science: Territorial Themes in the Shaping of Knowledge. London: Springer.

AIDMI. (2018). Understanding Uncertainty: Views from Kachchh, Mumbai and Sundarbans. In Special Issue no. 169, May 2018. Ahmedabad: All India Disaster Mitigation Institute. 
Barrett, W., \& Wittgenstein, L. (1978). The Illusion of Technique: A Search for Meaning in a Technological Civilization. Garden City, NY: Anchor Press.

Benessia, A., Funtowicz, S., Bradshaw, G., Ferri, F., Ráez-Luna, E. F., \& Medina, C. P. (2012). Hybridizing Sustainability: Towards a New Praxis for the Present Human Predicament. Sustainability Science, 7(1), 75-89.

Bhatt, M., Mehta, L., Bose, S., Adam, H. N., Srivastava, S., Ghosh, U., . . Pattak, V. (2018). Bridging the Gaps in Understandings of Uncertainty and Climate Change: Roundtable Reports August 2018. In Experience Learning Series 74: All India Disaster Mitigation Institute.

Bremer, S., \& Meisch, S. (2017). Co-Production in Climate Change Research: Reviewing Different Perspectives. Wiley Interdisciplinary Reviews: Climate Change, $8(6)$, e 482.

Burnham, M., Ma, Z., \& Zhang, B. (2016). Making Sense of Climate Change: Hybrid Epistemologies, Socio-Natural Assemblages and Smallholder Knowledge. Area, 48(1), $18-26$.

Carey, M. (2010). In the Shadow of Melting Glaciers: Climate Change and Andean Society. Oxford: Oxford University Press.

Coen, D. R. (2012). The Earthquake Observers: Disaster Science from Lisbon to Richter. Chicago: University of Chicago Press.

Corburn, J. (2003). Bringing Local Knowledge into Environmental Decision Making: Improving Urban Planning for Communities at Risk. Journal of Planning Education and Research, 22(4), 420-433.

Dyson, F. (2015). Dreams of Earth and Sky. New York: New York Review of Books.

Edwards, P. N. (2010). A Vast Machine: Computer Models, Climate Data, and the Politics of Global Warming. Cambridge, MA: MIT Press.

Eriksen, S. H., Nightingale, A. J., \& Eakin, H. (2015). Reframing Adaptation: The Political Nature of Climate Change Adaptation. Global Environmental Change, 35, 523-533.

Fairhead, J., \& Leach, M. (1996). Misreading the African Landscape: Society and Ecology in a Forest-Savanna Mosaic (Vol. 90). Cambridge: Cambridge University Press.

Flohn, H. (1954). Witterung und Klima in Mitteleuropa: mit regionalen Beitragaegen von Friedrich Lauscher über Oesterrech und von Max Schueepp. New York: S. Hirzel.

Goldman, M. J., Daly, M., \& Lovell, E. J. (2016). Exploring Multiple Ontologies of Drought in Agro-Pastoral Regions of Northern Tanzania: A Topological Approach. Area, 48(1), 27-33.

Goldman, M. J., Turner, M. D., \& Daly, M. (2018). A Critical Political Ecology of Human Dimensions of Climate Change: Epistemology, Ontology, and Ethics. Wiley Interdisciplinary Reviews: Climate Change, 9(4), e526.

Grevsmühl, S. V. (2016). Images, Imagination and the Global Environment: Towards an Interdisciplinary Research Agenda on Global Environmental Images. Geo: Geography and Environment, 3(2), e00020.

Hajer, M. A. (1995). The Politics of Environmental Discourse: Ecological Modernization and Policy Process. Oxford: Clarendon Press.

Hastrup, K., \& Skrydstrup, M. (2012). The Social Life of Climate Change Models: Anticipating Nature (Vol. 8). London: Routledge.

Hegger, D., \& Dieperink, C. (2015). Joint Knowledge Production for Climate Change Adaptation: what Is in It for Science? Ecology and Society, 20(4), 1.

Heymann, M. (2019). The Climate Change Dilemma: Big Science, the Globalizing of Climate and the Loss of the Human Scale. Regional Environmental Change, 19(6), 1549-1560. 
Hulme, M. (2010). Problems with Making and Governing Global Kinds of Knowledge. Global Environmental Change, 20(4), 558-564.

Hulme, M. (2012). How Climate Models Gain and Exercise Authority. In The Social Life of Climate Change Models (pp. 40-54). London: Routledge.

Huntington, H. P. (2011). The Local Perspective. Nature, 478(7368), 182-183.

Ingold, T. (2003). Globes and Spheres: The Topology of Environmentalism. In Environmentalism (pp. 39-50). London: Routledge.

Jasanoff, S. (2004a). States of Knowledge: The Co-Production of Science and Social Order. London: Routledge.

Jasanoff, S. (Ed.) (2004b). States of Knowledge: The Co-Production of Science and Social Order. London and New York: Routledge.

Jasanoff, S. (2010). A New Climate for Society. Theory, Culture \& Society, 27(2-3), 233-253.

Lane, S. N., Odoni, N., Landström, C., Whatmore, S. J., Ward, N., \& Bradley, S. (2011). Doing Flood Risk Science Differently: An Experiment in Radical Scientific Method. Transactions of the Institute of British Geographers, 36(1), 15-36.

Li, T. M. (2007). The Will to Improve: Governmentality, Development, and the Practice of Politics. Durham, NC: Duke University Press.

Lidskog, R. (2008). Scientised Citizens and Democratised Science. Re-Assessing the Expert-Lay Divide. Journal of Risk Research, 11(1-2), 69-86.

Mahony, M., \& Hulme, M. (2016). Modelling and the Nation: Institutionalising Climate Prediction in the UK, 1988-92. Minerva, 54(4), 445-470.

Masinde, E. M. (2012). Bridge between African Indigenous Knowledge and Modern Science on Drought Prediction. Cape Town: University of Cape Town.

Masinde, M. (2014). An Effective Drought Early Warning System for Sub-Saharan Africa: Integrating Modern and Indigenous Approaches. Paper presented at the Proceedings of the Southern African Institute for Computer Scientist and Information Technologists Annual Conference 2014 on SAICSIT 2014 Empowered by Technology.

Mazel-Cabasse, C. (2017). Hybrid Disasters-Hybrid Knowledge. In Resilience: A New Paradigm of Nuclear Safety. From Accident Mitigation to Resilient Society Facing Extreme Situations (pp. 337-351). Cham: Springer.

Mehta, L. and Srivastava, S.) 'Uncertainty in Modelling Change: The Possibilities of Coproduction through Knowledge Pluralism', in Scoones, I. and Stirling, A. The Politics of Uncertainty: Challenges of Transformation, Routledge pp 99-113

Mehta, L., Adam, H. N., \& Srivastava, S. (2019). Unpacking Uncertainty and Climate Change from 'Above' and 'Below'. Regional Environment Change, 19, 1529-1532.

Mol, A. (2002). The Body Multiple: Ontology in Medical Practice. Durham, NC: Duke University Press.

Nakashima, D., Krupnik, I., \& Rubis, J. T. (2018). Indigenous Knowledge for Climate Change Assessment and Adaptation. Cambridge: Cambridge University Press.

Nakashima, D., McLean, K. G., Thulstrup, H. D., Castillo, A. R., \& Rubis, J. T. (2012). Weathering Uncertainty: Traditional Knowledge for Climate Change Assessment and Adaptation. Paris: United Nations Educational, Scientific and Cultural Organization.

Nightingale, A. J. (2016). Adaptive Scholarship and Situated Knowledges? Hybrid Methodologies and Plural Epistemologies in Climate Change Adaptation Research. Area, 48(1), 41-47.

Nyong, A., Adesina, F., \& Elasha, B. O. (2007). The Value of Indigenous Knowledge in Climate Change Mitigation and Adaptation Strategies in the African Sahel. Mitigation and Adaptation Strategies for Global Change, 12(5), 787-797. 
Ophir, A., \& Shapin, S. (1991). The Place of Knowledge: A Methodological Survey. Science in Context, 4, 3-21.

Ostrom, E., Parks, R. B., Whitaker, G. P., \& Percy, S. L. (1978). The Public Service Production Process: A Framework for Analyzing Police Services. Policy Studies Journal, 7, 381 .

Parthasarathy, D. (2016). Decentralization, Pluralization, Balkanization? Challenges for Disaster Mitigation and Governance in Mumbai. Habitat International, 52, 26-34.

Patankar, A., \& Patwardhan, A. (2016). Estimating the Uninsured Losses Due to Extreme Weather Events and Implications for Informal Sector Vulnerability: A Case Study of Mumbai, India. Natural hazards, 80(1), 285-310.

Raymond, C. M., Fazey, I., Reed, M. S., Stringer, L. C., Robinson, G. M., \& Evely, A. C. (2010). Integrating Local and Scientific Knowledge for Environmental Management. Journal of Environmental Management, 91(8), 1766-1777.

Reid, K. A., Williams, K. J., \& Paine, M. S. (2011). Hybrid Knowledge: Place, Practice, and Knowing in a Volunteer Ecological Restoration Project. Ecology and Society, 16(3), 19.

Roe, E. (1994). Narrative Policy Analysis: Theory and Practice. Durham, NC: Duke University Press.

Rudiak-Gould, P. (2012). Promiscuous Corroboration and Climate Change Translation: A Case Study from the Marshall Islands. Global Environmental Change, 22(1), 46-54.

Rudiak-Gould, P. (2013). "We Have Seen It with Our Own Eyes": Why We Disagree about Climate Change Visibility. Weather, Climate, and Society, 5(2), 120-132. doi:10.1175/WCAS-D-12-00034.1

Rudiak-Gould, P. (2014). The Influence of Science Communication on Indigenous Climate Change Perception: Theoretical and Practical Implications. Human Ecology, 42(1), 75-86. doi:10.1007/s10745-013-9605-9

Schneider, B., \& Walsh, L. (2019). The Politics of Zoom: Problems with Downscaling Climate Visualizations. Geo: Geography and Environment, 6(1), e00070.

Shackley, S., \& Wynne, B. (1996). Representing Uncertainty in Global Climate Change Science and Policy: Boundary-Ordering Devices and Authority. Science, Technology E Human Values, 21(3), 275-302.

Smith, L. A., \& Stern, N. (2011). Uncertainty in Science and Its Role in Climate Policy. Philosophical Transactions of the Royal Society A: Mathematical, Physical and Engineering Sciences, 369(1956), 4818-4841.

Speranza, C. I., Kiteme, B., Ambenje, P., Wiesmann, U., \& Makali, S. (2010). Indigenous Knowledge Related to Climate Variability and Change: Insights from Droughts in Semi-Arid Areas of Former Makueni District, Kenya. Climatic Change, 100(2), 295-315.

Stirling, A. (2006). From Science and Society to Science in Society. Paper presented at the Towards a Framework for Co-operative Research. Report to the European Commission Workshop Governance and Scientific Advice. Brussels.

Stirling, A. (2010). Keep it Complex. Nature, 468(7327), 1029-1031.

Thomas, D., \& Twyman, C. (2004). Good or Bad Rangeland? Hybrid Knowledge, Science, and Local Understandings of Vegetation Dynamics in the Kalahari. Land degradation \& Development, 15(3), 215-231.

Walker, W. E., Harremoës, P., Rotmans, J., van der Sluijs, J. P., van Asselt, M. B., Janssen, P., \& Krayer von Krauss, M. P. (2003). Defining Uncertainty: A Conceptual Basis for Uncertainty Management in Model-Based Decision Support. Integrated Assessment, 4(1), 5-17.

Walker, W. E., Lempert, R. J., \& Kwakkel, J. H. (2012). Deep Uncertainty. Delft University of Technology, 1, 2 . 
Watts, N., Adger, W. N., Ayeb-Karlsson, S., Bai, Y., Byass, P., Campbell-Lendrum, D., ... Depledge, M. (2017). The Lancet Countdown: Tracking Progress on Health and Climate Change. The Lancet, 389(10074), 1151-1164.

Williams, T., \& Hardison, P. (2013). Culture, Law, Risk and Governance: Contexts of Traditional Knowledge in Climate Change Adaptation. In Climate Change and Indigenous Peoples in the United States (pp. 23-36). Cham: Springer.

Wynne, B. (1996). May the Sheep Safely Graze?. In W. S. Lash, B. Szerszynski i B. Wynne (red.). Risk, Environment and Modernity. In: London: Sage Publications Ltd. 